$$
\text { أدب الرحلات العربي في نيجيريا: شعر إسحاق أيوب ببأويَي أنموذجا }
$$

\title{
Arabic Literature of Travelogue in Nigeria: A Case Study of Ishaq Ayyub Baba-Oye's Poems
}

\author{
JamiuSaadullahAbdulkareem \\ Department of Arabic, Faculty of Arts, University of Ilorin, Ilorin, Nigeria \\ abdulkareem.js@unilorin.edu.ng
}

\begin{abstract}
الملنحص
يعتبر أدب الرحلات العربي أحد الفنون الأدببة التي عني بها الأدباء النيجيريون منذ القرن العشرين الميلادي، ولا سيما لإفادته القراء

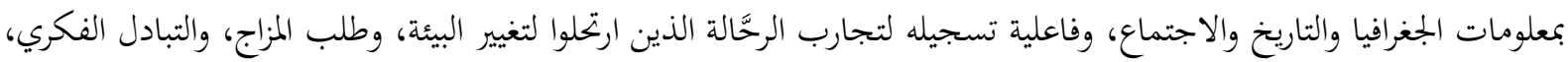

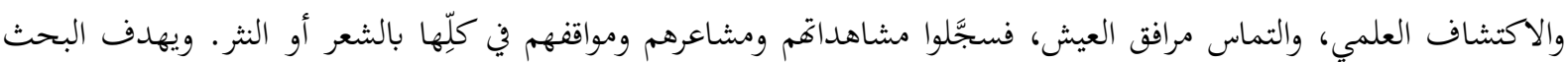

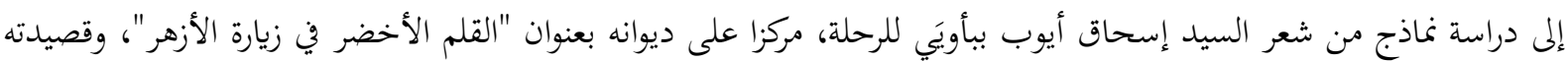
بعنوان "استغِلَّ هذا المجال للتعرف على قرية العربية بإنغال"، وقد تم اختيار هذين العملين الرحليين لعلم الباحث أهما لم ينالا عناية دارسي العربية بنيجيريا حتى الوقت الراهن. وكان استعمال المنهج التاريخي لدراسة تاريخ أدب الرحلات العربي وأعلامه في نيجيريا

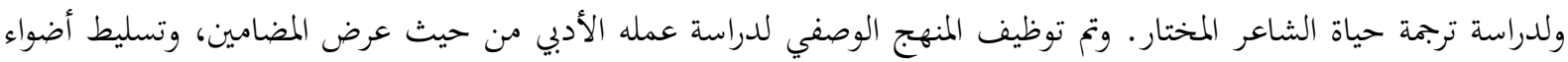

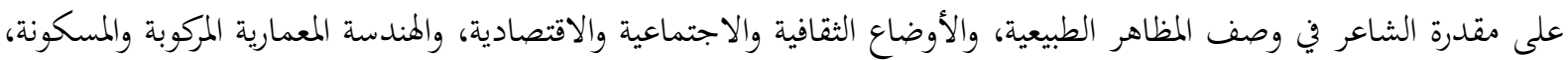

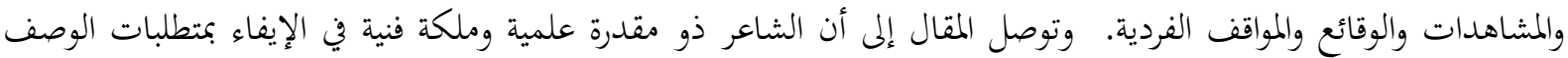
الرحلي الذي يتطلب توخي دقة المضمون وروعة الشكل؛ ولذا اقترح للقراء مراجعة العمل لمنافعه العلمية والفنية. الكلمات المفتاحية: الأدب، العربي، الرحلات، نيجيريا، إسحاق ببأويَي.
\end{abstract}

\begin{abstract}
The art of travelogue is one of the Arabic literary trends in Nigeria, as scholars admired it since the twentieth century by writing poetry or prose, due to its aim at imparting the knowledge of geographical descriptions, historic facts and societal development in the readers and documenting the scholars' experiences from various travels which could be for the acquisition of ascetic, cultural, diplomatic and socio-economic values, The main objectives of the study were to determine the extent at which the selected literary works of Is-haq Ayyub Baba-Oye, as a case study, met the requirements of the art of travelogue with contents analysis. The selected poet, is considered as one of the admirers of the art of travelogue, as proven by his two literary works on travels to Ngala-Maiduguri of Nigeria and Cairo of Egypt Republic. The methodology adopted is both historical and descriptive. It is historical by presenting the background of the art of travelogue in the Nigerian Arabic literature, then identification of scholars involved, followed by the biography of the poet. It is descriptive, as contents of selected works were unveiled while discourse analysis of the artistic and critical features was handled with formative and thematic measures. It was noticed that the author did the justice to the genre to his best capability, therefore, the work is recommended for readers for the benefits of the contents and embellishments.
\end{abstract}

Keywords: Arabic, Literature, Travelogue, Nigeria, Is-haq Baba-Oye.

Article History:

Received: 2/10/2021 Accepted: 8/10/2021
Published: 10/11/2021 
الرحلات نشاط حضاري فعَّال، يؤثِّر في حياة البشر الثقافية والاجتماعية والدينية والاقتصادية، من فاعلية تغيير البيئة للمزاج والتبادل الفكري، والاكتشاف العلمي، والتماس مرافق العيش؛ فسجَّل أدباؤها مشاهداتم

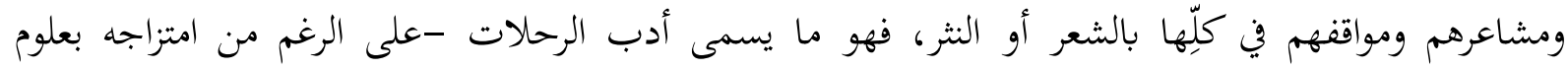

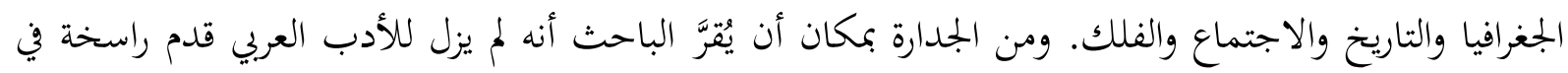

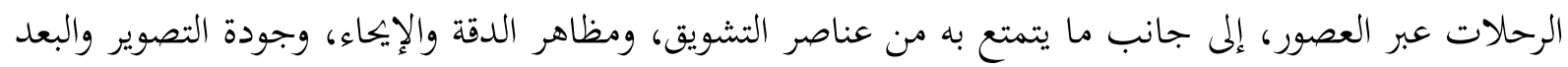

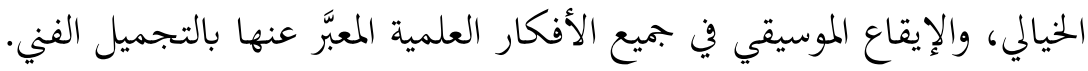

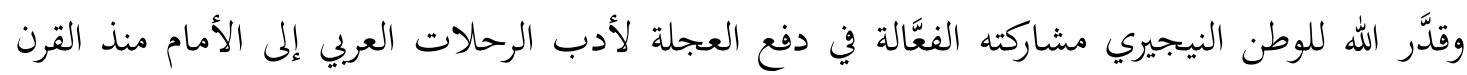

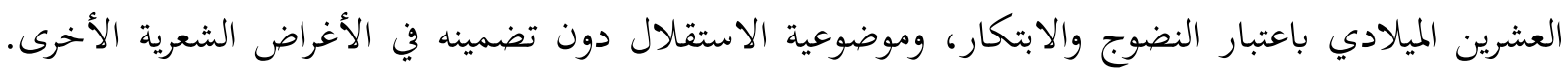

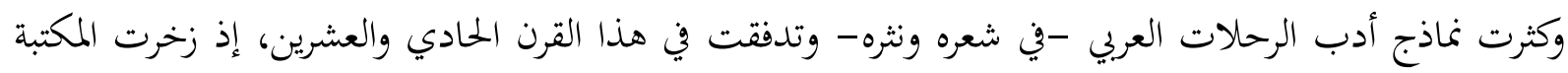

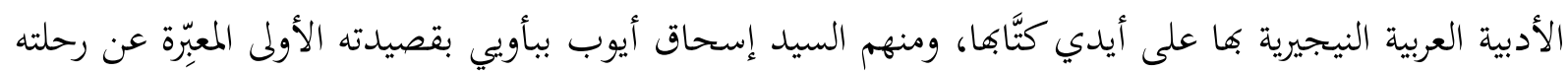

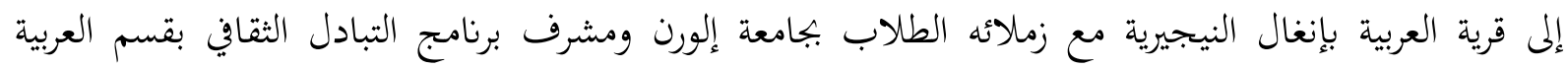

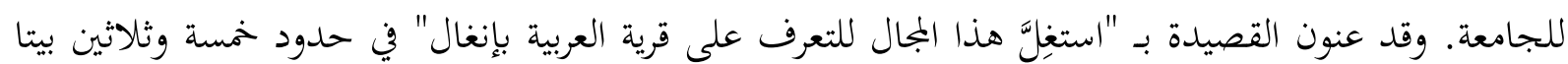

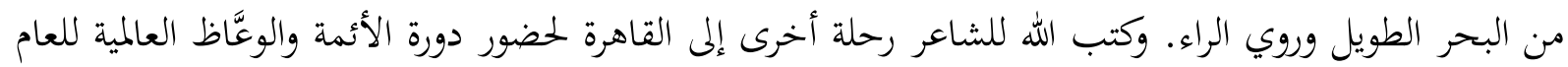

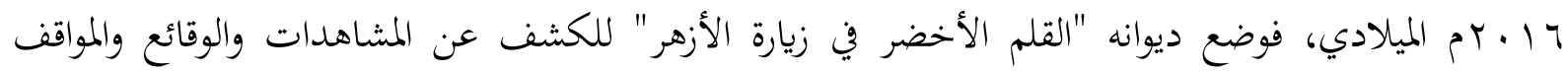
الفردية بشتى الاتحاهات التي منها الاقتصادي والاجتماعي والوصفي والعلمي والثقافي وغيره.

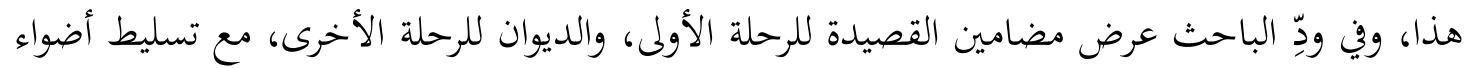

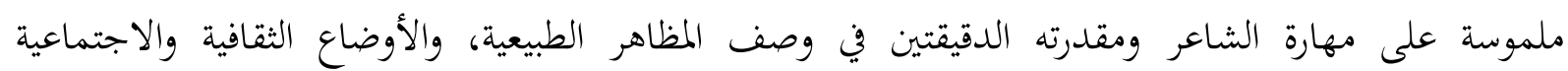

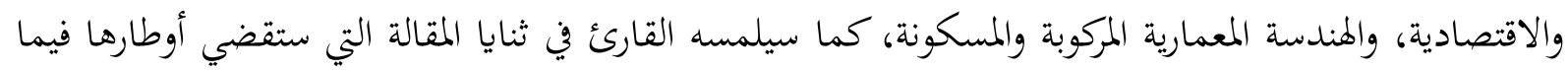

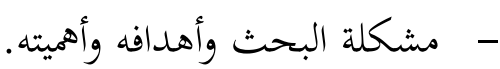

$$
\begin{aligned}
& \text { - - مفهوم الرحلات وتطورها في التاريخ الأدبي العربي. } \\
& \text { - أدب الرحلات العربي في نيجيريا. } \\
& \text { - ترجمة حياة الشاعر إسحاق أيوب ببأوبي. } \\
& \text { - الدراسة الوصفية للنموذجين في أدب الرحلات العربي عند الشاعر. }
\end{aligned}
$$


DOI: https://doi.org/10.22452/aldad.vol5no1.7

e-ISSN: 2637-1146

https://ejournal.um.edu.my/index.php/aldaad/index

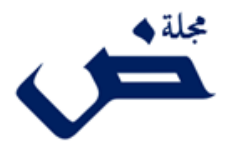

مشكلة البحث وأهدافه وأهميته

عني الإنسان بحب الاستطلاع والمغامرة والتشوق الشديد إلى استكشاف المجهول، مما جعل الأدب ألمابل

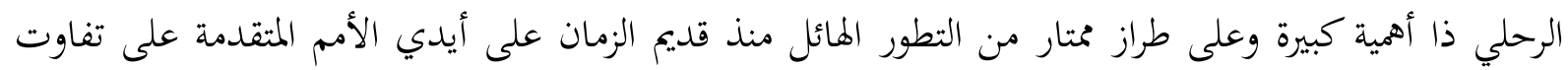

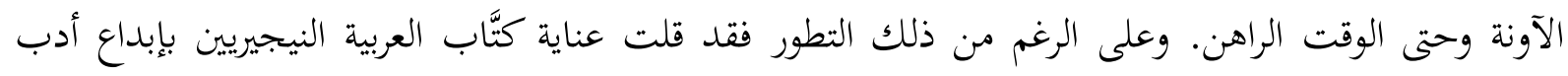

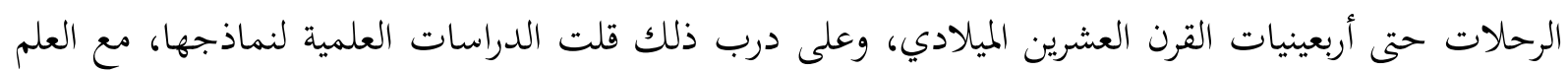

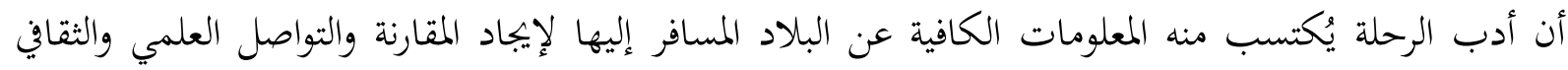

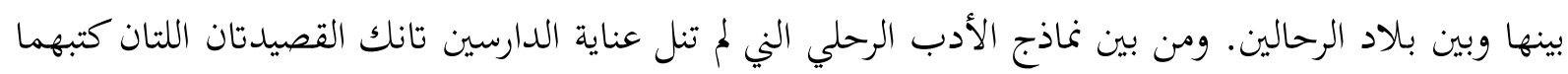

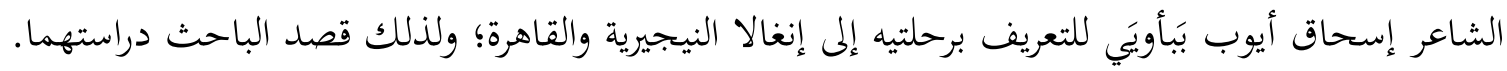

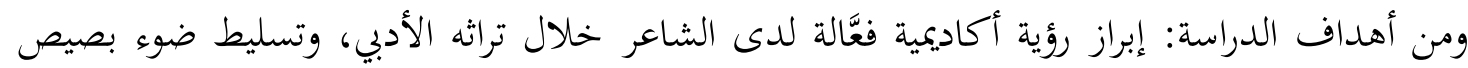

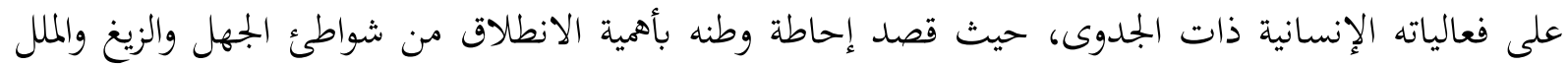

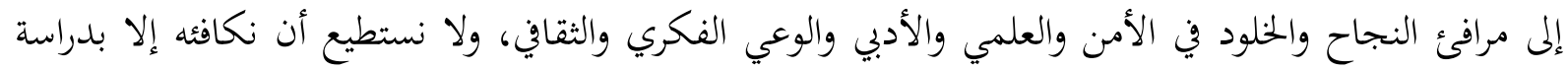

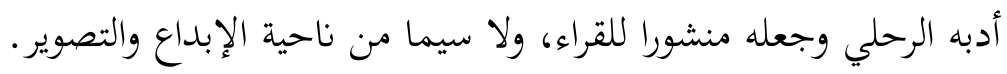

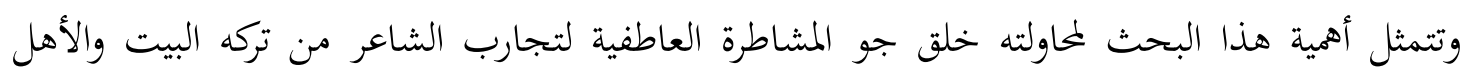

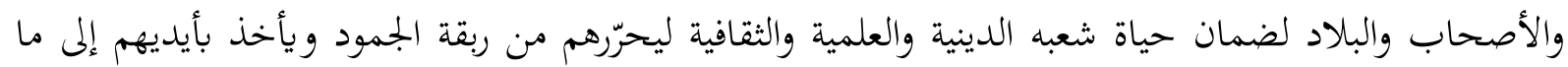

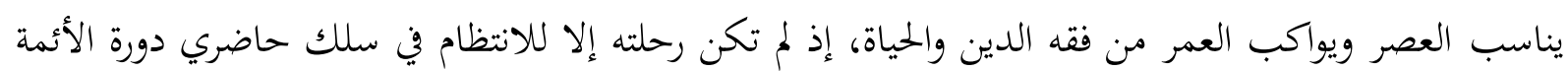
والوعاظ الدولية بالقاهرة- مصر، فيستفيد معلوماها لنفع العباد ورفع البلاد. مفهوم الرحلات وتطورها في التاريخ الأدبي العربي

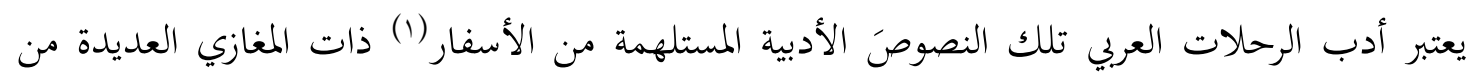

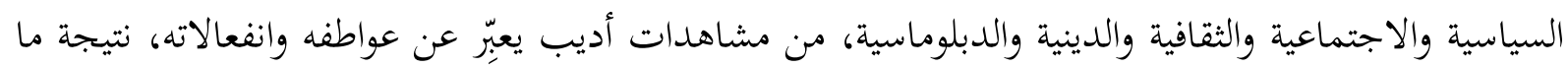
يمتلكه من عناصر التشويق الفني للمظاهر الطبيعية والعمرانية والدينية والتربوية والاقتصادية.

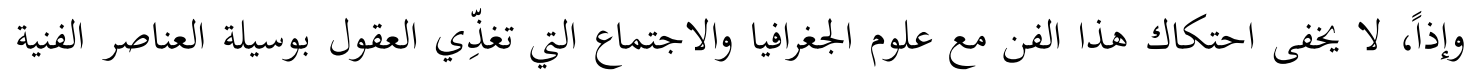

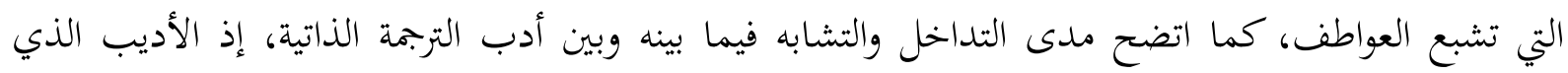

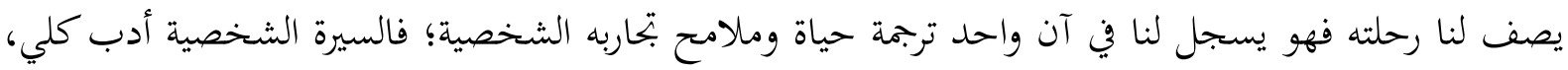
والرحلات جزء منه. (r)

ا - مصلح الدين يوسف المرتضى: الاتحاهات الفنية في أدب الرحلة لعلماء بلاد يوربا- رحلتا "من إلورن إلى تمبكتو" و"هكذا ابتليت" نموذجا، ورقة

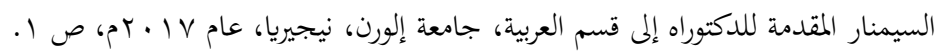

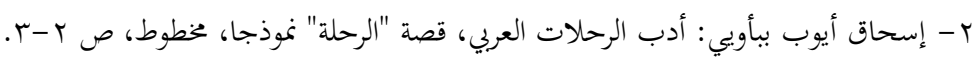


وكانت الأصول اللغوية لأدب الرحلة من: رحل عن المكان رحلا ورحيلا وترحالا إذا سار ومضى، ورحل

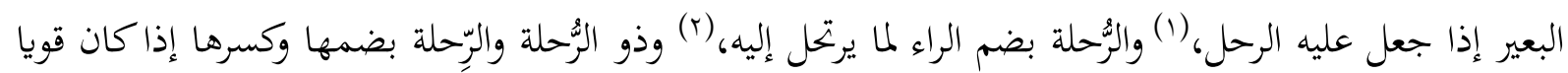

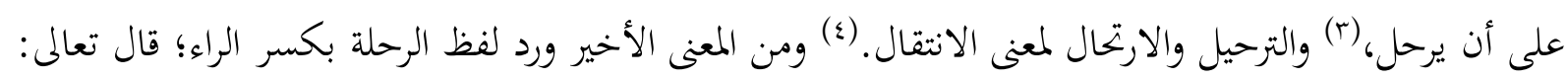

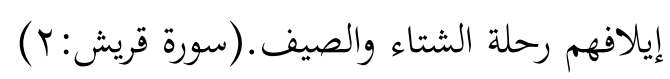

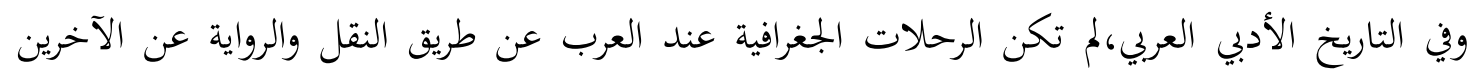

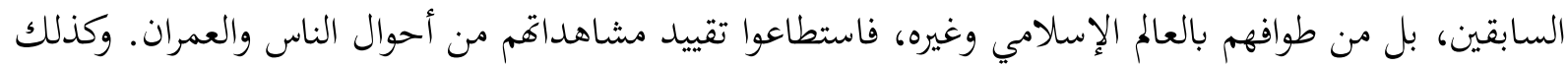

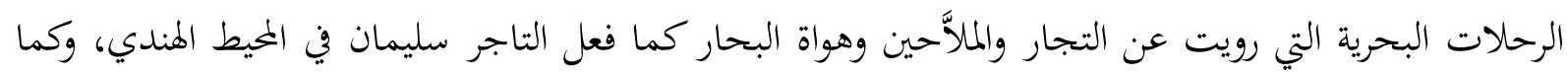

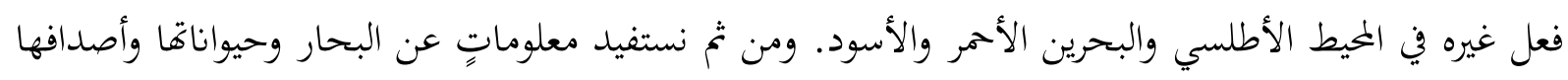

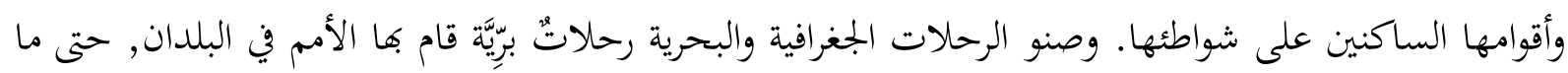

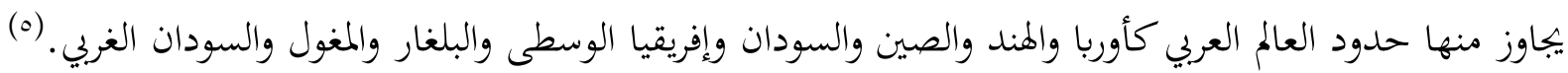

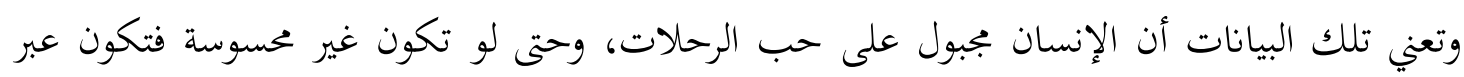

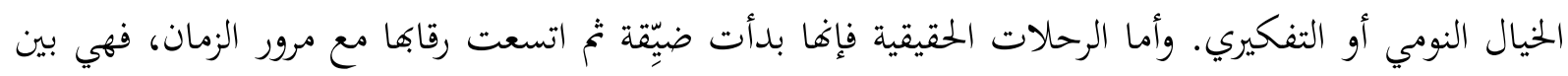

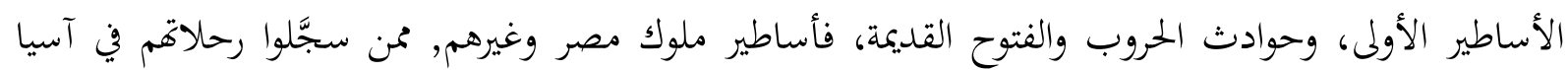

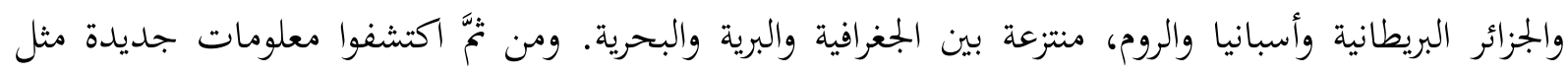

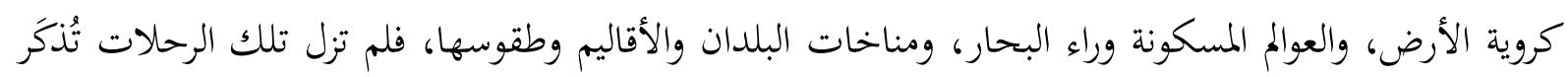

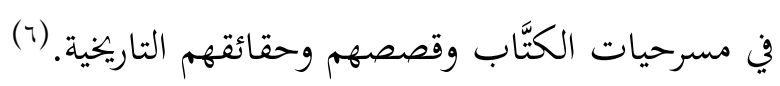

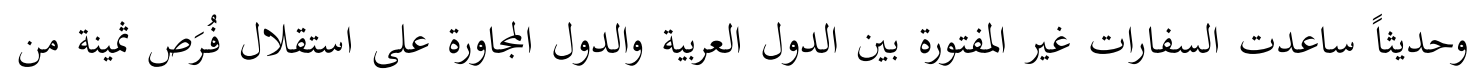

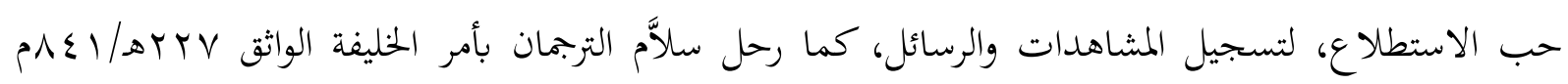

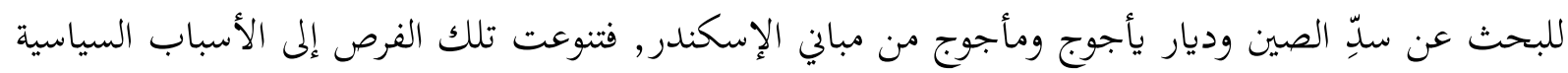

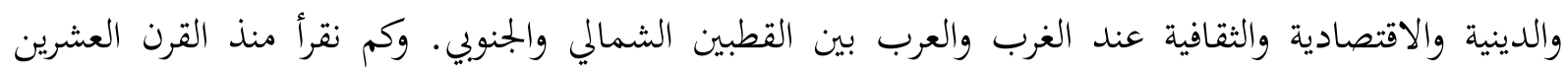

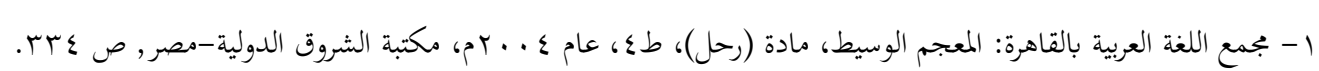

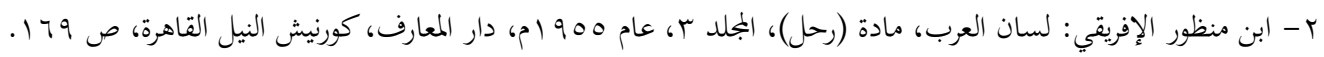

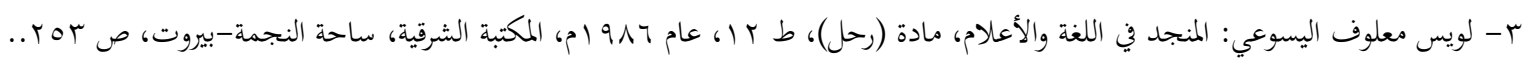

$$
\begin{aligned}
& \text { ع - المرجع نفسه، والصفحة نفسها. }
\end{aligned}
$$

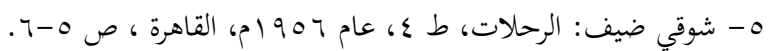

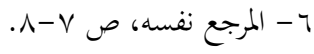


DOI: https://doi.org/10.22452/aldad.vol5no1.7

e-ISSN: 2637-1146

https://ejournal.um.edu.my/index.php/aldaad/index

الميلادي من روايات فنية تُعتبر نماذج أدب الرحلات العربي في الفن القصصي متَّ يبرهن عن حب العرب

والمستعربين للمغامرات والمجازفات. (1)

ومن نماذج الرحلات الجغرافية عند العرب: كتاب المسالك والممالك وكتاب صورة الأرض لابن حوقل في

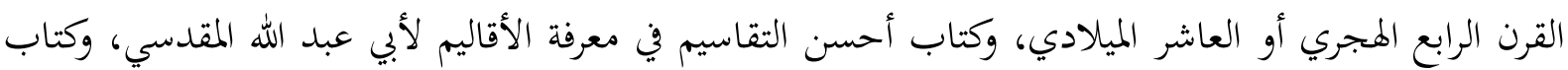

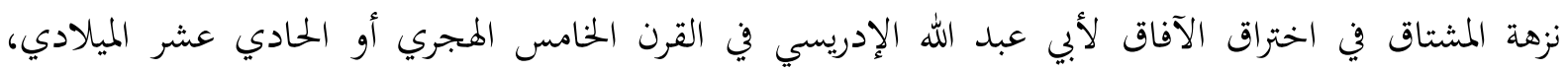

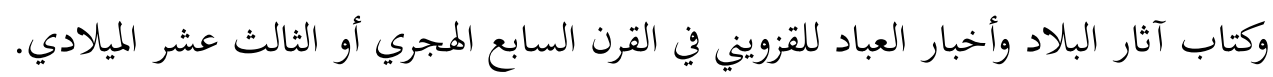

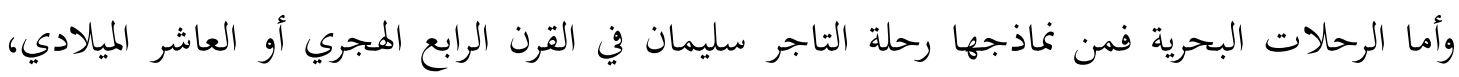
وكتاب عجائب الهند برّه وبحره وجزائره للمستشرق بزرك بن شهريار الناخداه.

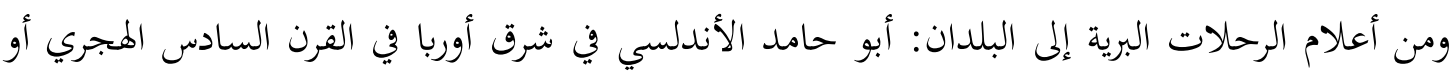

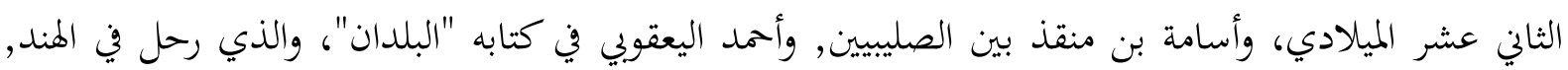

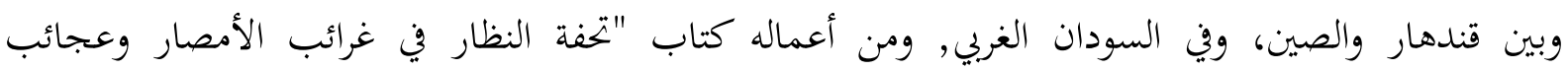

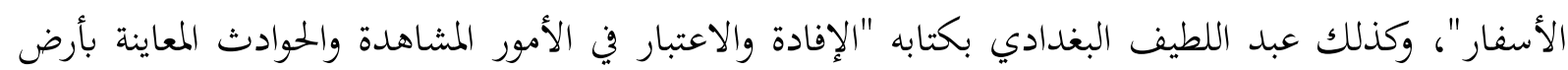

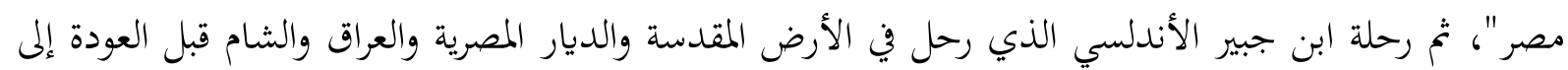

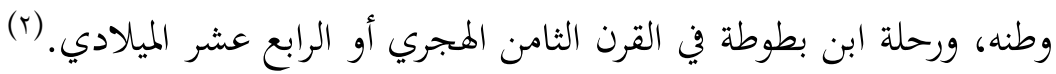

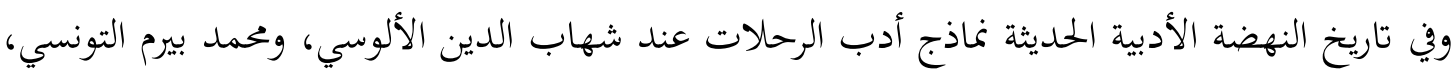

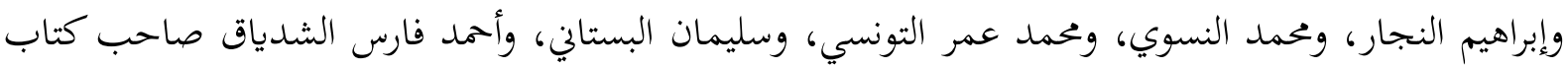

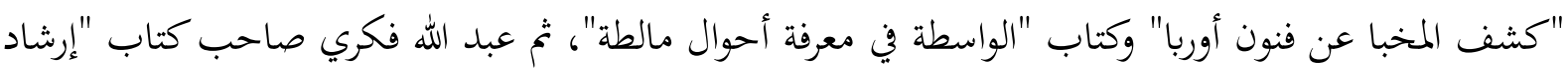

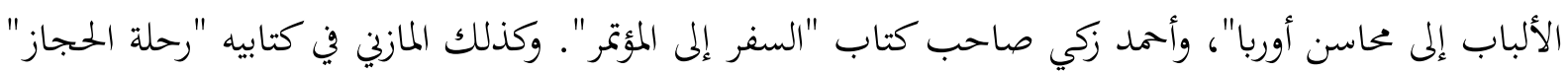

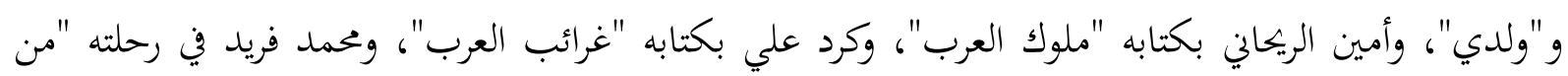

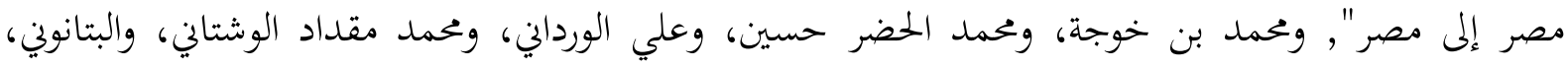

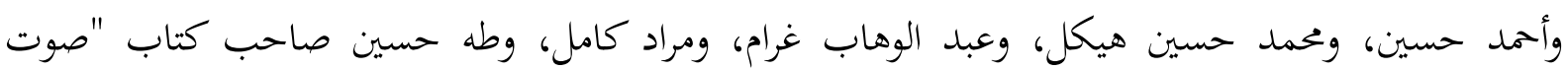

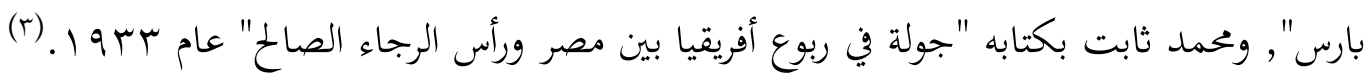

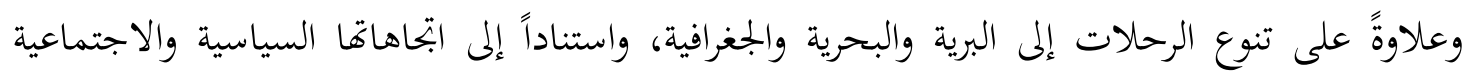

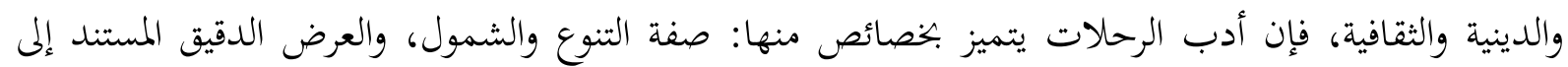


الاختيار الشخصي والمشاهدات الواقعية، والرأي الممحض، والاتحاه نخو تحري الحقيقة في الوصف والتصوير،

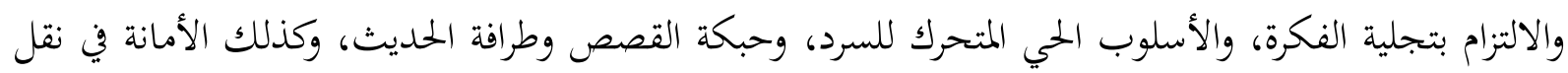

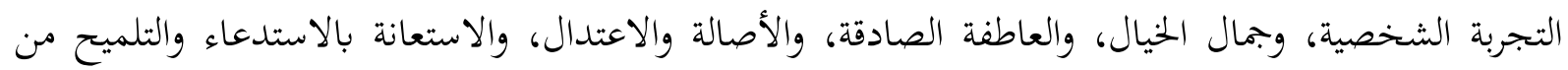

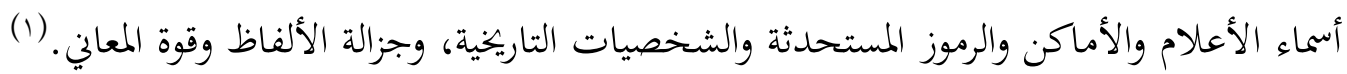

\section{أدب الرحلات العربي في نيجيريا}

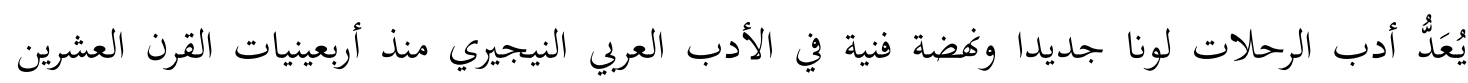

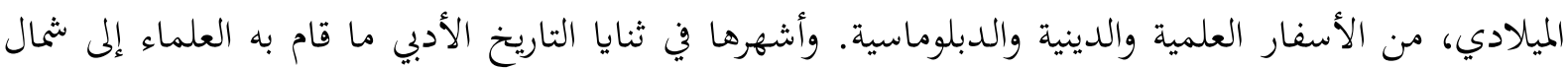

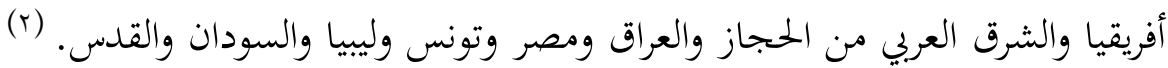

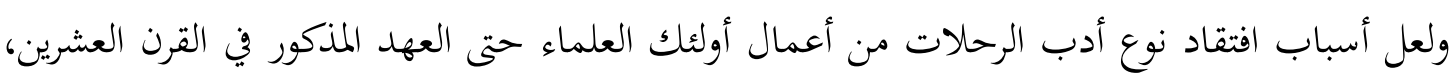

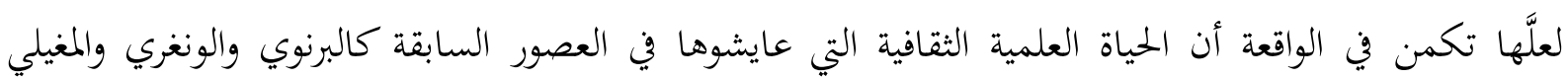

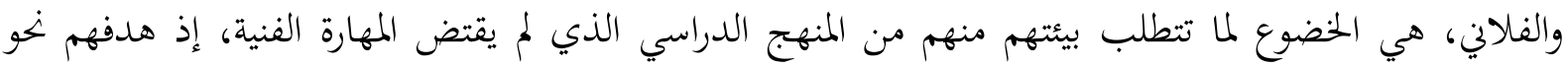

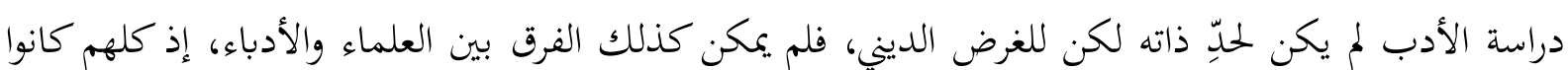

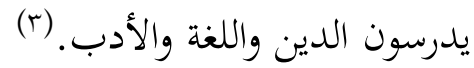
وكذلك في العصر الفلاني، علماً بأن حياتم عهدئذ لم تتكلف جهد رحلةٍ خارج نطاق المنطقة... إذ ولذ

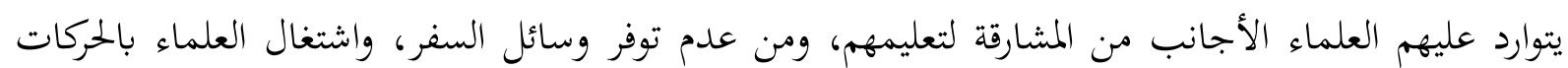

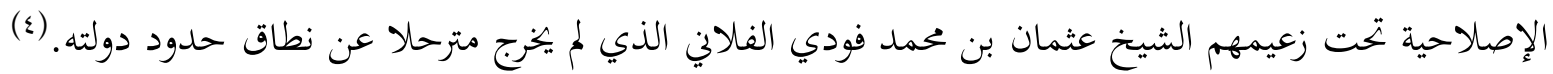

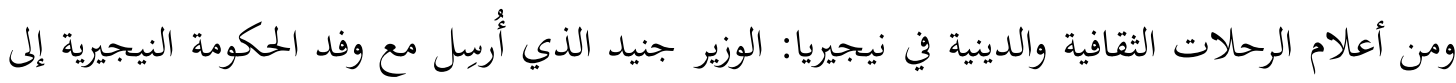

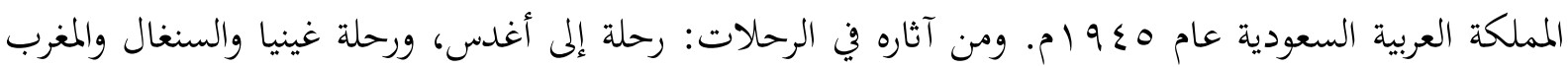

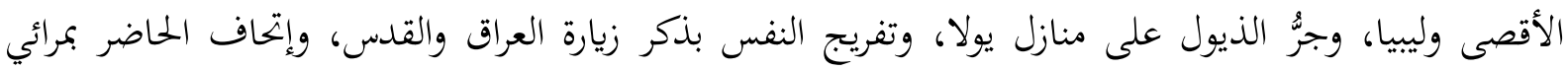

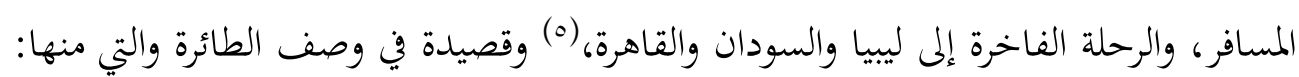

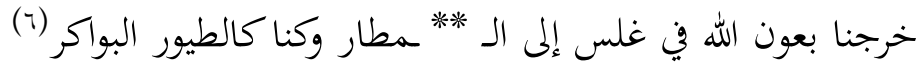

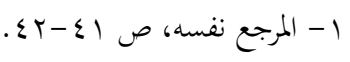

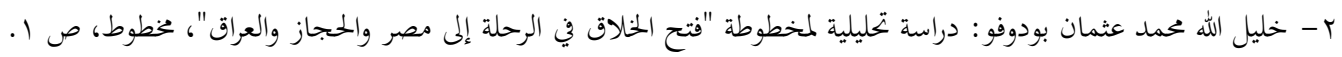

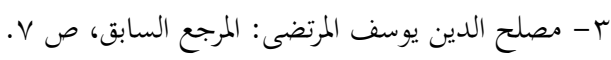

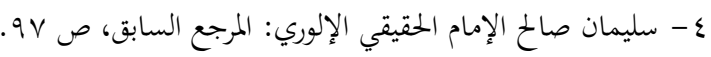

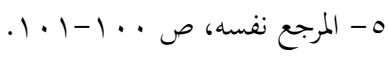

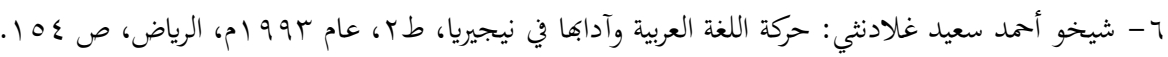


يا من يصعِدِ أنفاسا بأنفاس *** شوق بخرطوم ذات الورد والآس(1)

ثم العلامة آدم عبد الله الإلوري في قصيدته اليائية التي تنص على رحلته إلى مصر ومنها:

أيا قاصدا أرض نيجيريا أبلغن *** سلامي إلى أصحابها متراضيا

وقل لهُ أني أعود إليهمو *** إذا عسعس الليل تر الصبح آتيا

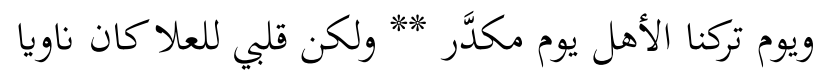

وصلنا إلى الخرطوم بعد مشقة ** نحاول إذنا عند من كان ناهيا

إلى أن أجزنا أرض السودان كلها *** وصرنا إلى الشلاًَّل نطوي الفيافيا

وها أنا هذا اليوم في مصر بالهنا *** وكان ابن مَنْبَلا معي سعدُ تاليا

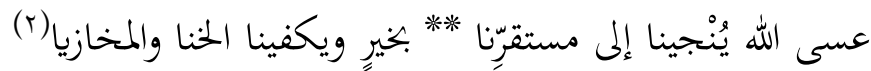

ومن بعده إمام مدينة بوشي الشيخ محمد بن محمد بلو الملقب بسَركن التفسير في رحلته مع الأمير يعقوب

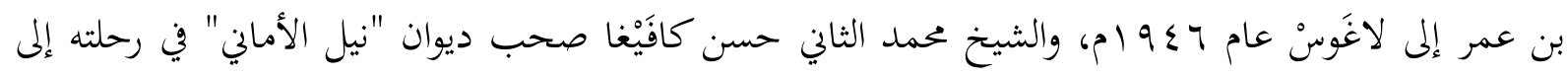
مدينة الكولح، والشيخ تيجاني عثمان رَنغُونُ بَري بَرَي الكنوي في رحلته إلى مقطعة بَرْنَنْ كُدُ "الرحلة الكدوية"، وإلى الكوخ "النفحات الإلهية في الرحلة الكولخية"، والشيخ ناصر كبرَ زعيم الحركة القادرية في غرب أفريقيا عموما بقصيدته "سلسبيل السنة في نفت كيسان شراب"، وكذلك الشيخ عثمان القلنسوي في منظومته "الروائع في بيان الرحلة القلنسوية" في رحلته إلى جمهورية السنغال لزيارة الشيخ إبراهيم الكولخي. ثم الشيخ مصطفى الهوسوي في رحلته السياحية "نشيد النزهة التغوية"، والشيخ أبوبكر المسكين البرنوي، والشيخ محمد فَنُ الكنوي في منظومته "رحلة الأنيس في ذكر رحلة الشيخ سيس"، والشيخ أبوبكر سَنكا في رحلته إلى مكة المكرمة لقضاء مناسك الحج بكتابه "الطيارة بقاصد الزيارة"، والشيخ أبو رمضان ثَنْثَنْ نَغاوا، وأحمد الرفاعي أبوبكر الكنوي، والشيخ محمد مَيْماسا الإلوري بمخطوطته "فتح الخلاق في الرحلة إلى مصر والحجاز والعراق" عام 9 و ام، والشاعر عيسى ألبي أبوبكر في رحلته إلى "غانا" وإسحاق أيوب ببأويي في قصيدته "استغلَّ هذا المجال للتعرف على قرية العربية بإنغال"

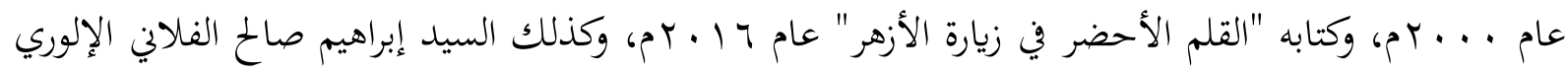

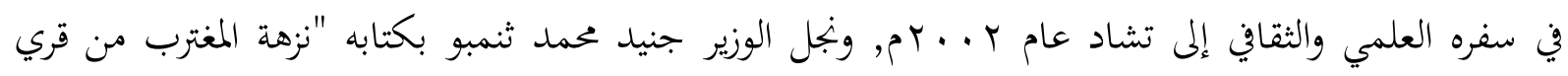
المغرِبِ" عام ب . .. بم، والسيد موسى سلمان الفارسي في قصيدته "وصف الرحلة العلمية إلى إنغالا"، والسيد أمين الله آدمو الغمبري، والسيد سليمان الحقيقي في رحلته إلى المدينة المنورة "في رحاب المدينة"، والأستاذ يهوذا 
أحمد غيطو في قصيدتيه "أشواق الوصال" و "نعيم الجنتين لزائر الحرمين"، والأستاذ نوح إبراهيم باز الله الإلوري في

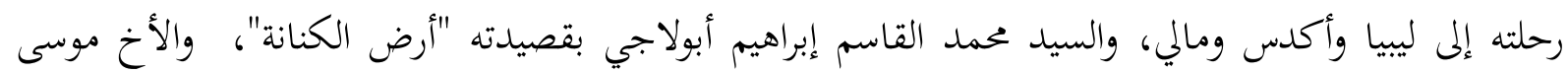

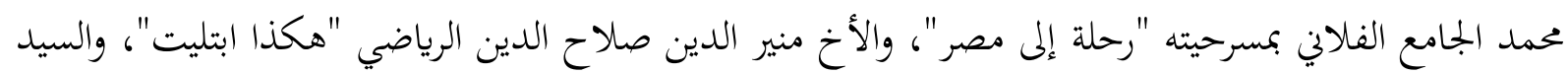

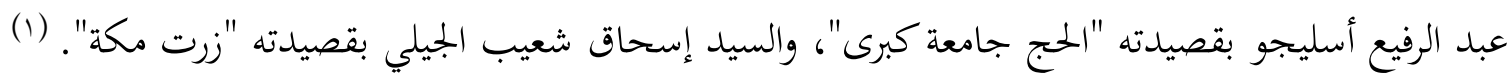

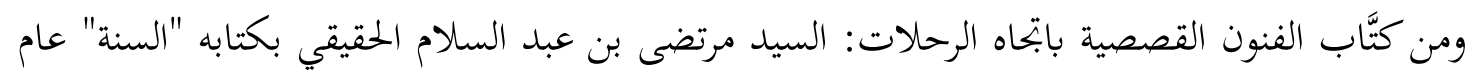

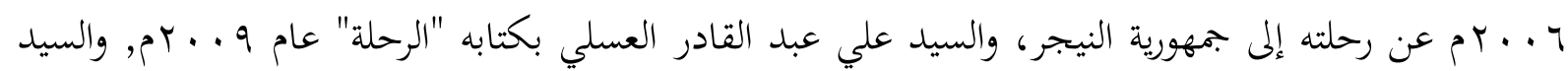

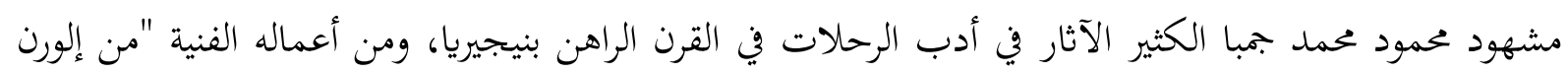

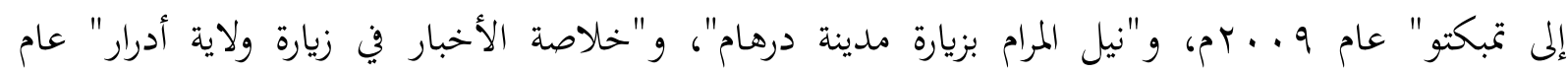

\section{ترجمة حياة الشاعر إسحاق أيوب ببأويي الإلوري:}

هو الشاعر إسحاق بن أيوب بن خضر بن محمد الثاني الإلوري. ولد بمدينة إلورن في سبعينيات القرن الإنوري:

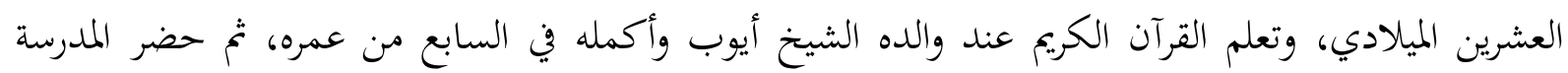

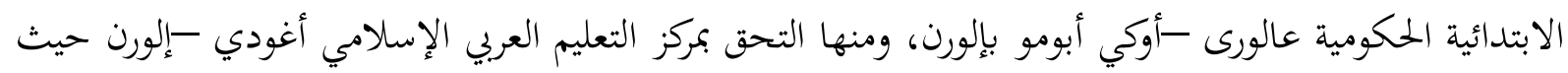

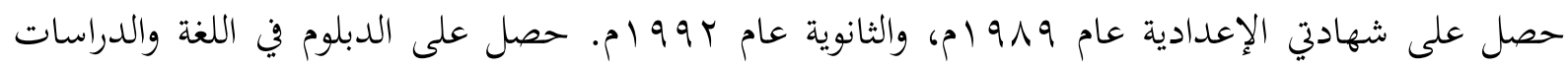

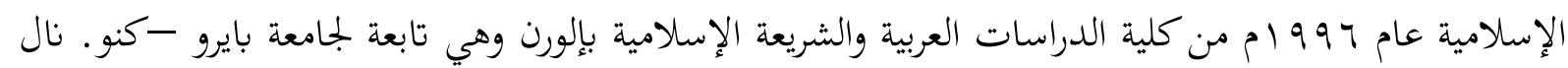

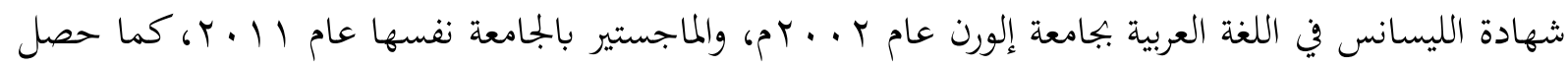

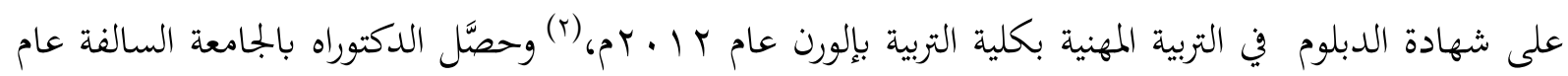

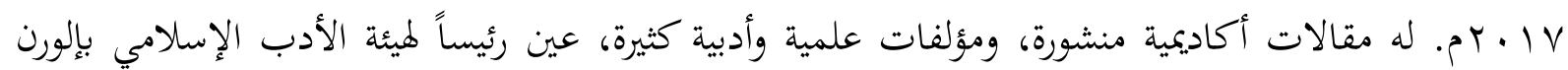

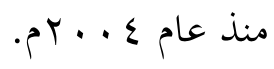

بذل الشاعر إسحاق ببأويَي جهودا كبيرة فائقة في تعاطي الشعر العربي بنيجيريا، وشاع صيت شاعريته في

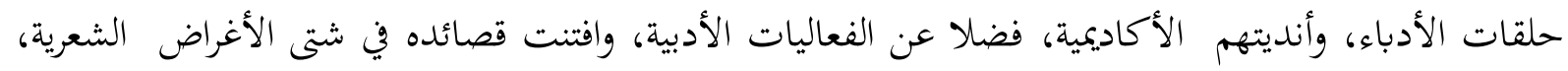

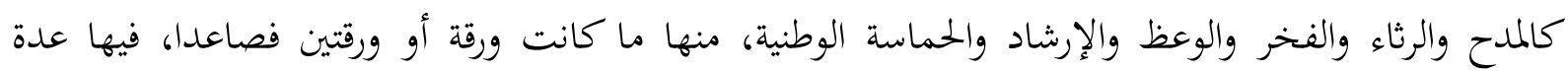

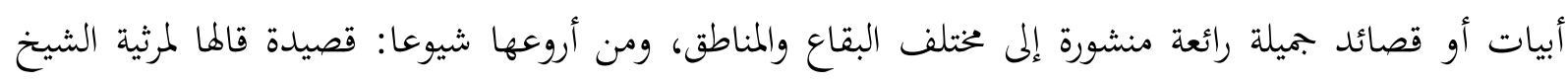

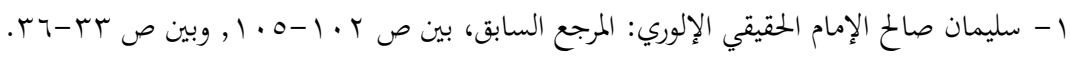

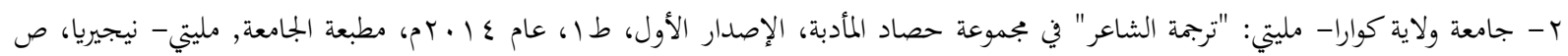


الفاضل آدم عبد الله الإلوري عام ب99 (9م، وقصيدته في مهرجان المسابقة الشعرية لمناسبة عيد الخمسين عاما من

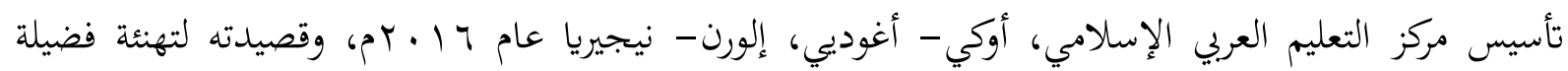

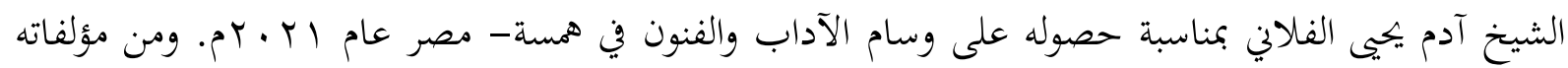
في الشعر العربي تخميس قصيدة قبا الذي شاع صيته في نيجيريا، يليه قصيدتاه الرحليتان اللتان هما نطاق هذه

\section{الدراسة الوصفية للنموذجين من أدب الرحلات العربي للشاعر}

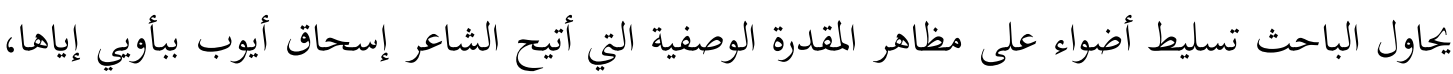

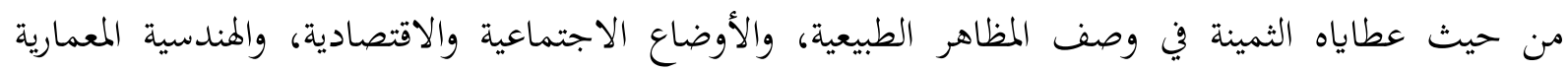
الحضارية والرجالات الثقافية التاريخية.

ويبدو للباحث أن القصيدة بعنوان "استغل هذا المجال للتعرف على قرية العربية بإنغال"، والديوان الشعري

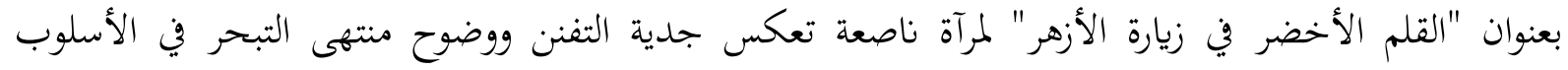

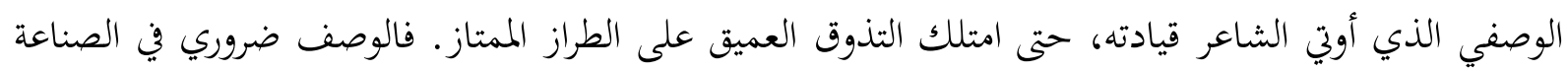

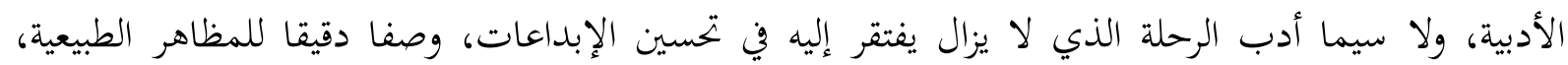
والهندسة المعمارية، والأوضاع الاجتماعية والاقتصادية والثقافية. وصف المظاهر الطبيعية:

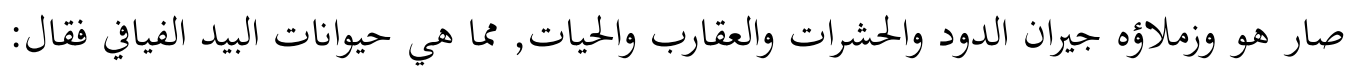

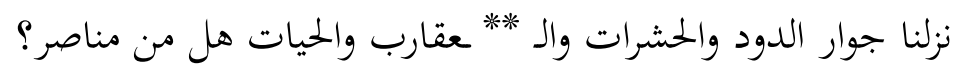

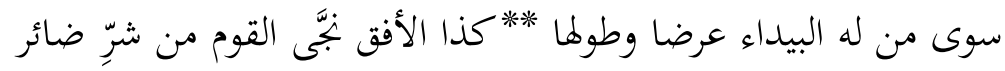

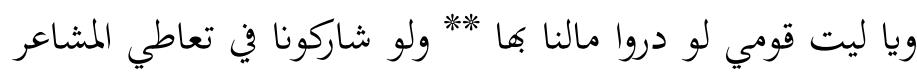

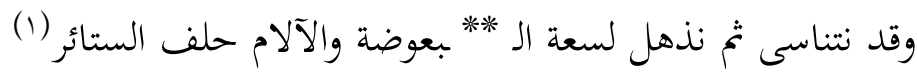

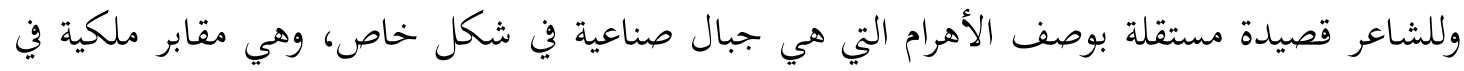

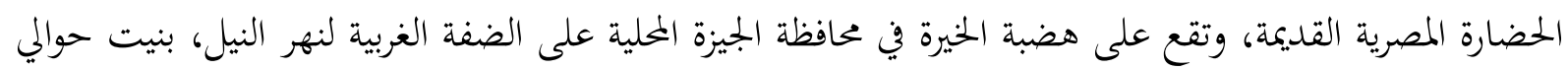

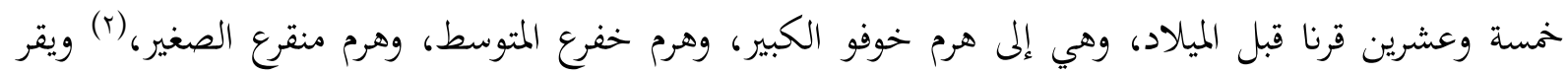

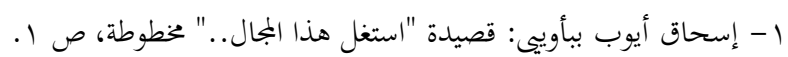

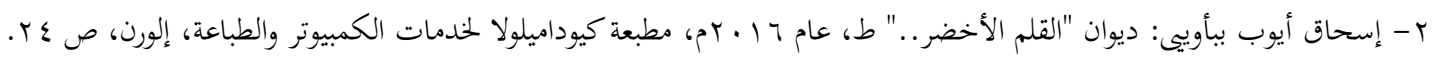


الشاعر تلك الأوصاف الدقيقة لها بقوله, متخيلا ضخامتها ومعجبا بها، ومنتهيا إلى أها من عجائب الدنيا التي تعرفت عليها الأعراب، ومن آثار عجبها استحالة ركوب أبعادها على الرغم من كوها صناعية:

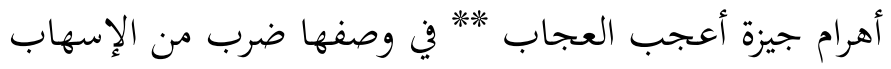

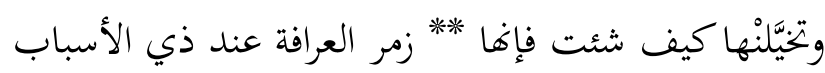

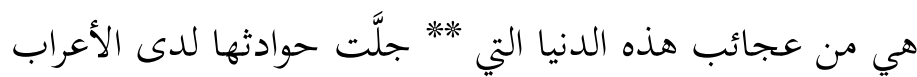

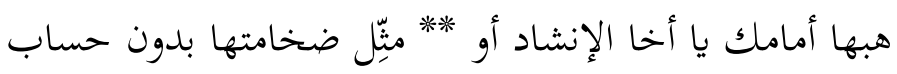

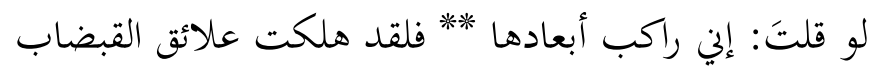

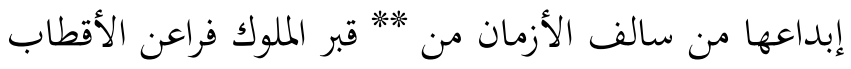

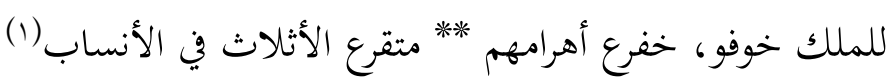

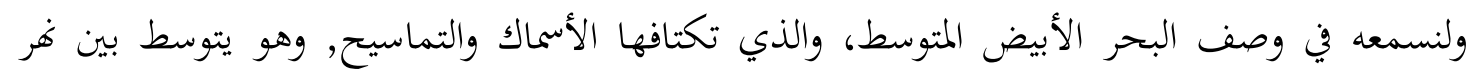

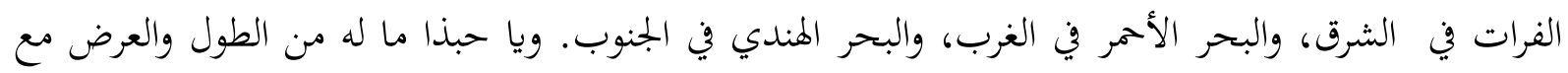

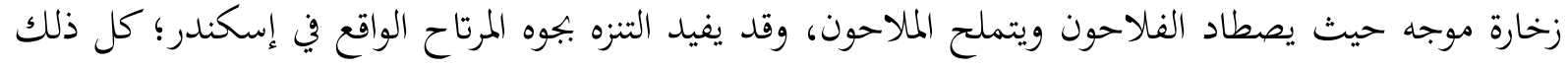

بزيزيرة العرب الكرام بحارها *** تكتافها الأسماك والتمساح

يختاطها غر الفرات بشرفها *** وبغربها حمر البحار قراح

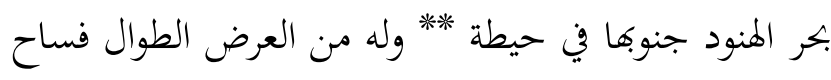

بشمال مصرٍ بحر أبيض ماؤه *** والفلك في أثنائه ترتاح

أبيض بحر زاخر أمواجه *** يصطاده الفلاح والملاح

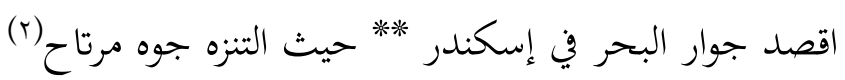

وصف الهندسة المعمارية:

ولا يزال الشاعر يصطفُ في صف المعجبين بكل ما يروق من صنائع المهندسين المركوبة والمسكونة؛ ولذا

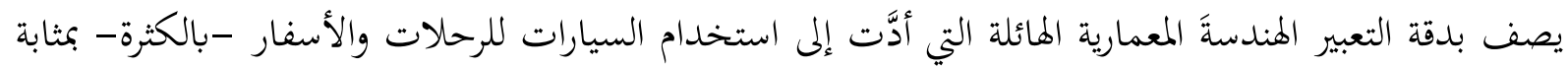

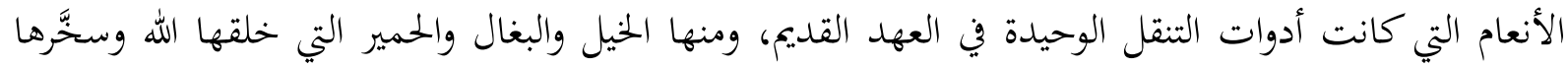

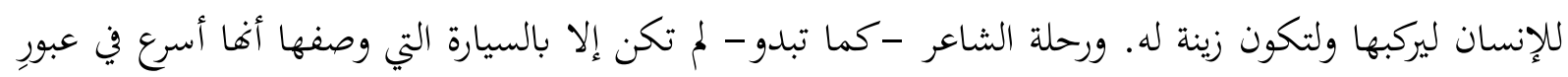

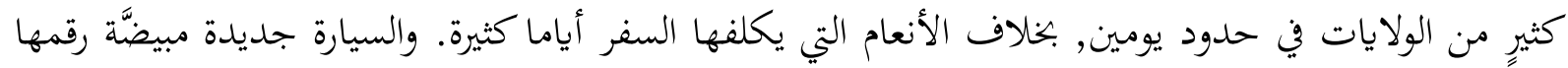


ABUJA XA 847-GWA تَسَعُ خمسة عشر شخصا باستثناء السائق, وصلوا بها إلى قرية إنغال التي تبعد عن كن مدينة ميدغوري عاصمة برنو بمائة وستة وثلاثين كيلومتر، بينها وبين حدود كاميرون نحو ثلاثة كيلومتر. والشاعر يجيطنا علما بكل ذلك في قوله: خرجنا بأمر الحقل جامعة البلد *** إلى قرية عربية في المظاهر وتعدادنا في خمسة بعد عشرة *** وسائقنا بل مع سموٍّ المحاضر

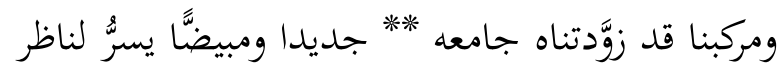
وسبع ولايات عبرنا طريقها *** بيومين لما عين بل في المهاجر كوار ونيجر بل كدونا وبعدها توترت العزمات من بعد فتلها *** تخافتت الأصوات دون تشاور

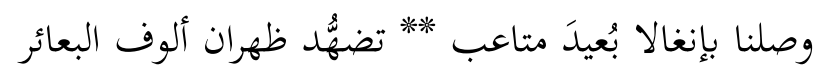
وصلنا بها الاثنين أين في مسائه *** وصول الحجاج بالمنى للشعائر (1) وصنو السيارة من معالم الهندسة القطارُ الكهربائي Metro الذي ركبها الشاعر بالقاهرة، وقد استخرج من ركوبه عظاتٍ يعتبرها رشيدة للتفكر في صنع الله ولإتقان بفناء الدنيا وما فيها، إذ كانوا لا يزالون يسايرونه في مينائه على قبور الموتى، ذلك أن مسيره أقرب إلى القبور من الشوارع؛ ولكنه مع ذلك سريع السير من صناعات الصين الكهربائية؛ وسندرك كل ذلك في قوله:

$$
\begin{aligned}
& \text { أيتها المترو التي *** قد أذهلتني سيرها } \\
& \text { أُدرجِتُ في مينائها ** تحت الطباق لركبها } \\
& \text { فسألت هل لذوي الحيا *** قبور موتى قومها }
\end{aligned}
$$

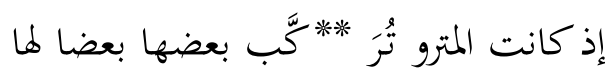

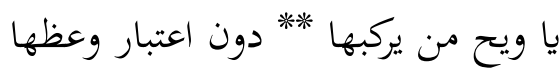

$$
\begin{aligned}
& \text { ينزل قوم عندما ** يعلو سواهم متنها } \\
& \text { هذي طبيعة الحيا }
\end{aligned}
$$

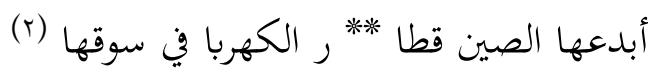

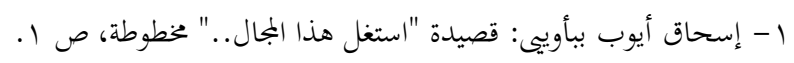

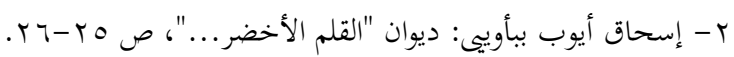


وأما الهندسة المعمارية المسكونة، فهي ممتزجة بالثقافة العلمية، حيث يصف الشاعر المكتبات العامرة بالعلوم والمعارف، معجبا بطرق بنائها وبتحيدها. فقال في شأن المكتبات والقاعات والأزوقِة في قرية إنغال بعدد ذكر السبب الدافع إلى تحمل المشقات من السفر:

$$
\begin{aligned}
& \text { لما نستفيد من شعور ومنظر *** علوما وآدابا وكنز المآثر } \\
& \text { ومكتبة فيها لجاحظ نسبةً *** وقاعات أعلام سطوعي المخابر } \\
& \text { وأزوقِة الطلاب ثم منازل الـ ** عمال لها أسماء شرق الحواضر (1) }
\end{aligned}
$$

ومثال ما سبق من القول، وصفه المكتبة الإسكندرية التي تقع في شمال مصر العبية بساحل البحر الأبيض المتوسط، والتي تبعد عن القاهرة بمائتين وتلاثين كلومتر، وفيها مُزارات الصحابي أبي الدرداء، وأبي العباس المرسي، والإمام البوصيري صاحب البردة.(r) والمكتبة عامرة العلوم والفنون والمعارف على تنوع اللغات العالمية الراقية واختلاف الأمم والشعب، فهي قديمة من عهد بابل واليونان ومصر، مجددة الآلات النفاذة في الثقافة والحضارة، بالإضافة إلى معمارية أطباقها وقصورها, وشعاعة بلَّورها في الشمس والقمر , وعراقة طوابيرها على كثرة

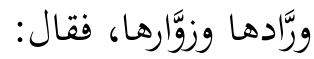

$$
\begin{aligned}
& \text { أسكندريةُ دارَ الكتب والعبر *** معمارها يرذري بالقصر في البهر } \\
& \text { أُعطيتِ حقا لورَّادٍ أتوك من الـ ** أسفار من أبيض أو أسود الصور } \\
& \text { زوَّدت عقلهمُ بالعلم والحكم **م عن عهد بابل واليونان والمصر } \\
& \text { فيها اكتشاف علوم الفن والفلك *** مع النجوم وعلم الدين والأثر } \\
& \text { با حبذا كان الأسكندار مكتبةً *** حديثة الآلة النفاذة النِبَر } \\
& \text { أكثرِّر بها عند طابور الحصول على ** تذكار إيرادها في الليل والنهر }
\end{aligned}
$$

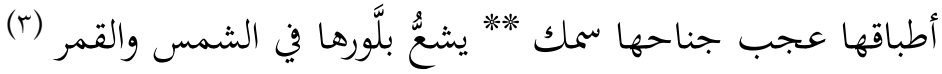

\section{وصف الأوضاع الثقافية والاجتماعية والاقتصادية: \\ وإلى جانب المظاهر الطبيعة والهندسة المعمارية بنوعيها، هناك وصف الأوضاع الثقافية والاجتماعية والاقتصادية في أدب الرحلات العربي للشاعر. ومثلا في قصيدته "استغل هذا المجال..." يقرٌ الشاعر الثقافة العلمية والأدبية بالعربية الراسخة القدمين في الوطن النيجيري منذ سبعة قرون قبل استعمار بريطانيا على البلاد، فتلك}

$$
\begin{aligned}
& \text { 1- إسحاق أيوب ببأويى: قصيدة "استغل هذا المجال..." مخطوطة، ص ا-؟Y. }
\end{aligned}
$$

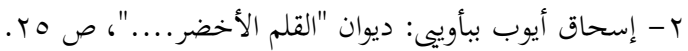

$$
\begin{aligned}
& \text { ب- المرجع نفسه، والصفحة نفسها. }
\end{aligned}
$$


الثقافة هي التي كانت الأجيال المتعاقبة يتوارثوها كابرا عن كابر, يشهد لها اعتناء الشاعر وزملائه بالعلم, على العى

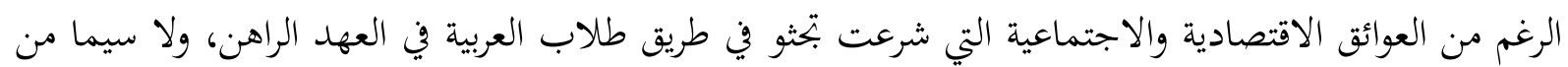

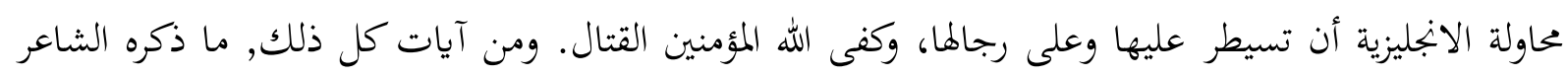
من حبهم الأثير للعلم وتوقير أعلامه فقال:

قصدنا طِلاب العلم والفن والحكم *** نواسي ببرد الصبح ألم الخواطر

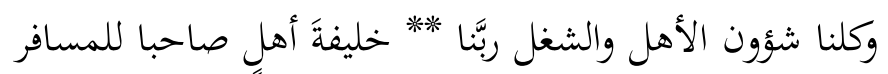

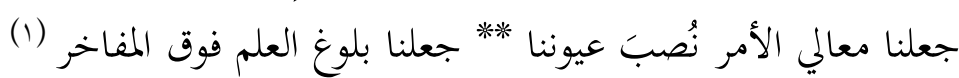

وانتهى الشاعر إلى ذكر أسماء المحاضرين لشتى المواد الدراسية بقرية العربية في إنغالا، وهم: الأستاذ محمود

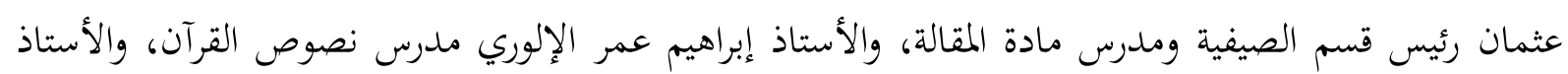

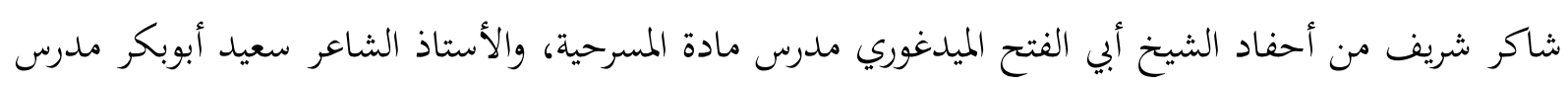

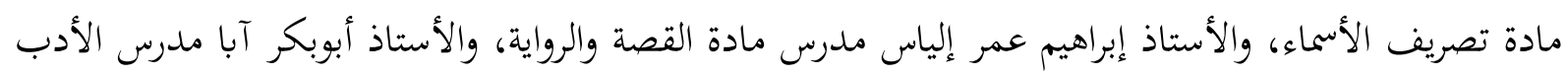

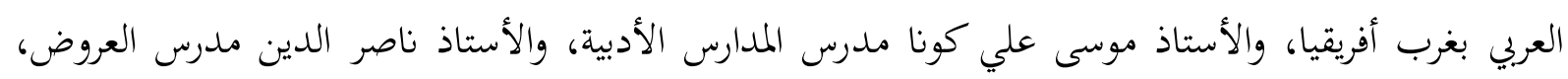

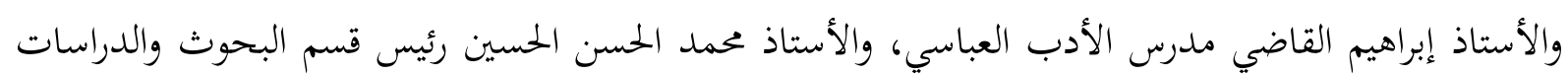

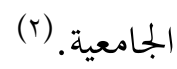

فلم يزل الشاعر يكزن على فراق أولئك الأساتذة وفراق القرية، لما يفتقده من المعارف والعلوم والآداب

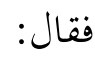

$$
\begin{aligned}
& \text { وجمع من العلماء أعظِمْ بعلمهم ** يُغذُّوننا من مثلجات الضمائر } \\
& \text { ألا يا رئيس القسم من سودان دي ت* * نميَّ الشؤون مقنعا بالبصائر }
\end{aligned}
$$

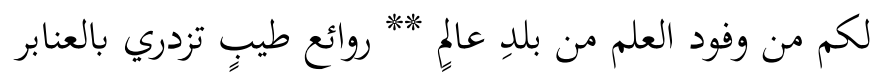

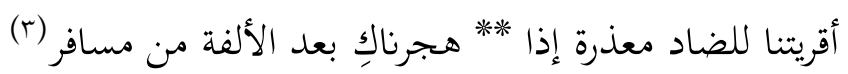

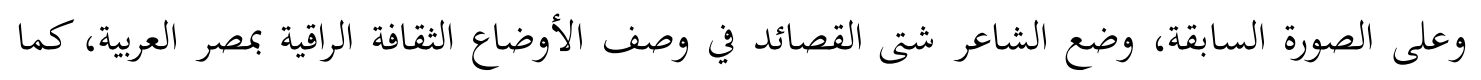

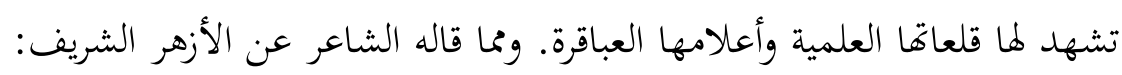
يأ أزهر سعد الورى بك يا تُرى *** وسما بك العلم الأصيل وأكبرا

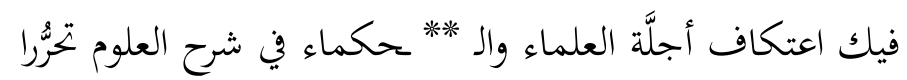

1 - إسحاق أيوب ببأوييى: قصيدة "استغل هذا المجال..." غخطوطة، ص 1.

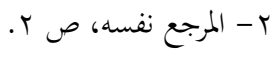
r- ب- المرجع نفسه، والصفحة نفسها، صنها. 


$$
\text { فنهم الأئمة في صفوف الأذكيا ** وهم الأعزة شأفم لن يُنكَرا }
$$

وعلى غرار ذلك، شرع الشاعر يصف أعلام العلوم والآداب والمعارف ويمدحهم بمهاراقم الخاصة:

كالشيخ أبي موسى البلاغي، والشيخ خولي برهم الناقد، والشيخ أحمد الهاشمي المحدِّث، والشيخ محمد ربيع الجوهري العقدي، والشيخ صبري محاضر الدراسات الشرقية، والشيخ زيدان الأصولي، والشيخ رمضان محاضر الفرائض، والشيخ حفنى محاضر تاريخ التشريع الإسلامي، والشيخ صابر الفقيه، والشيخ سعيد صلاح الدين عامر محاضر الفقه المقارن، والشيخ خالد عبد النبي عبد الرزاق محاضر مصطلح الحديث، والشيخ حسن الحميد المفسِّر، والشيخ جميل السيد هام، والشيخ محمود، والشيخ محمود صديق، والشيخ مذكور محمد علي محاضر القضايا المعاصرة، والشيخ محفوظ عقل الأديب، والشيخ فوزي مجوِد القراءات، والشيخ زكي المصطفى محاضر الحضارة الإسلامية، والشيخ يوسف سليم الاقتصادي؛ تظهر أسماؤهم في قصيدته بعنوان "مع الأعلام". (r) وغير أولئك المذكورين أعلام القراءات المبعوثون من قِبَل شيخ الأزهر إلى مدينة البعوث الإسلامية الأزهرية للوافدين، يرأسهم الشيخ المقرئ عماد عبد الرحمن آل قشطة ممثل جمهورية مصر العربية، والشيخ المقرئ عبد الرحمن عبد العزيز عبد الله السديس إمام الحرم المكي؛ وقد مدحهم الشاعر بقوله: يا فريق النور أهلا بالهنا ***نتمو أعلى الذرى في قلبنا

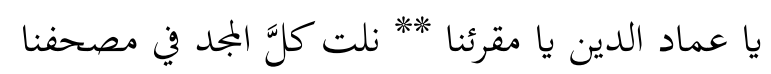

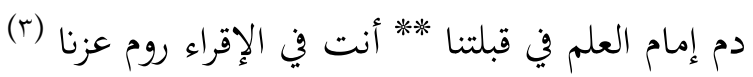
وكم نذكر من قصائد ارتحلها لترحيب المحاضرين ومدحهم وتقدير محاضراقم، منها ما هي لترحيب الشيخ محمد ذكي رزق بداري الأمين العام للجنة العليا للدعوة الإسلامية بمشيخة الأزهر الشريف في زيارته التفقدية، (ع)

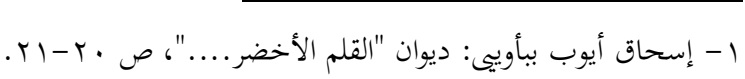

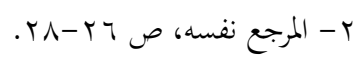

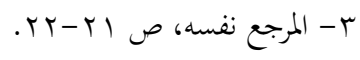

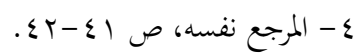


وقصيدة وصف محاضرة الدكتور رمضان عبد الرزاق للثقافة الإسلامية المعاصرة،(1) وقصيدة وصف محاضرة الأستاذ الدكتور أحمد سلامة سبع لعلم الفرائض،(r) وقصيدة وصف محاضرة الأستاذ الدكتور حسن أحمد حفنى في تاريخ التشريع الإسلامي، (r) وقصيدة وصف محاضرة الأستاذ الدكتور خالد عبد النبي عبد الرزاق في علوم الحديث، (ع) وقصيدة ترحيب مشرفي الدورة الأستاذ نادر القاضي والأستاذ محمد عبد العبود،(ه) وقصيدة الوصف لحلقة أبي موسى. (7) وقدَّر الشاعر أهل العلم حق التقدير، ولذا نشهلده مستعيدا أفكارنا إلى ذكر معالم الدين والتاريخ في الثقافة العربية بمصر، إذ حضر ذهنَه ذكرى الأقطاب في صون العلوم، وقد صاروا أجداثا، منهم الصحابة عمرو بن إنى العاص وأبو ذر الغفاري والحسين بن علي، والإمام الشافعي وأبي العباس المرسي الصوفي والبوصيري والسيوطي وصلاح الدين الأيوبي؛ ومن القصيدة:

$$
\begin{aligned}
& \text { أفضت الدمع في عرصات قوم *** محامدهم بُجحَلٌ ولا تُسام } \\
& \text { لهم في صفحة التاريخ بجد *** يردِده الأنام إذا استهاموا } \\
& \text { هم الأقطاب في صون العلوم ** هم الأبرار شأوهمُ سنام }
\end{aligned}
$$

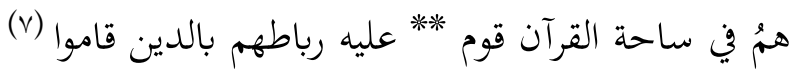

وعلى إثر ذلك، فوجئ بخبر وفاة الأستاذ الدكتور سيدي فرج عبد الحليم المتوفى في حادثة اصطدام

السيارة بالقاهرة، شاطر الشاعر بقصيدته أبناءَ مصر في رثائها فقال أبياتا منها:

$$
\begin{aligned}
& \text { يا سيدي فرج الحليم جرحتنا *** جرح الحمام شعورنا باللذعة } \\
& \text { يا مكنز الإعطاء في تعليمه *** أبشر فقد أحسنت عند العشرة } \\
& \text { يا منبع الإلهام في إلقائه *** وحرّكِك الأذهان رغم السكتة } \\
& \text { أرثيك بالشعر الحزين وقد مضى *قى في سنة الأدباء قول الحسرة } \\
& \text { لطف الإله بسيدي في قبره ** وأثابه عند القيام بنعمة } \\
& \text { شاء الإله رثاءه في العالم *** سودا وبيضا من حضور الدورة (1) }
\end{aligned}
$$

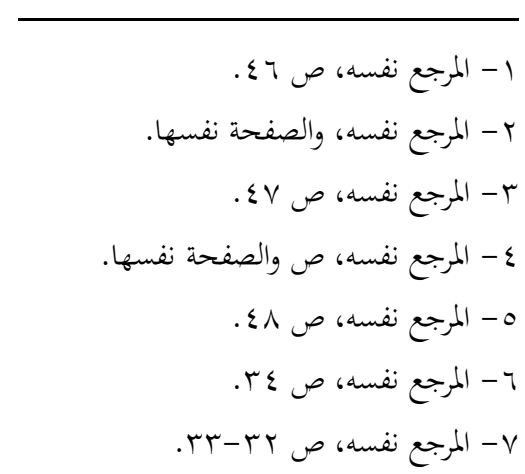


ومن كبار العلماء المعاصرين بنيجيريا فضيلة الشيخ داؤد ألفنلا عبد المجيد أيليخا, فالذي يعتبر أحد حملة لواء الشيخ آدم عبد الله الإلوري في مسيرة الدعوة والفلسفة والعلم والأدب والثقافة في نيجيريا وغيرها من بين دول غرب أفريقيا الراهنة. وقد ارتحل له الشاعر قصيدة ترحيبية عند زيارته لوفد الدورة بالقاهرة: أ بشرى زارنا خير الإمام *** ورمز الدين عند الاستهام

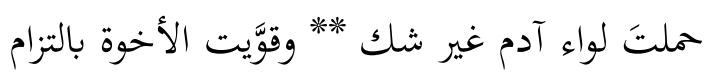
جعلت العلم فوق الجهل دوما *** جعلت الذكر فه الاستقام تجوب الأرض في نشر العلوم *** وتصفية القلوب من الركام

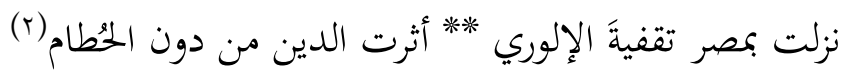

ولرغبة الشاعر الشديدة في تحصيل المنافع والحكم أينما كانت، يُرى أحدَ الحضور في المسابقة العلمية السنوية التي عقدها اتحاد طلبة كلية دار الكتاب والسنة الأزهري بمدينة البعوث الإسلامية، فقال عن المسابقة:

$$
\begin{aligned}
& \text { إن التسابق نجحة, كن حاذقا *** وبه يصير الخامل العملاقا } \\
& \text { واها لقد شاهدتُه وتمثَّلت ** أعطاؤه في ذهننا ترياقا } \\
& \text { وخُض التسابق لا تكن متثاقلا ***تحد التسابق عندنا إشفافا(r) }
\end{aligned}
$$

ومن آثار تقديره العلوم والآداب، قصيدته في تقريظ كتاب "الكواكب الدرية " للسيد عبد القادر يونس أوغانجا. والكتاب مجموعة المدائح النبوية التي وفِّق فيها الكاتب مصيبا لغرضه، ومنيبا إلى ربه بوسيلتها، وراجيا بها نيل أمانية، فكأنه ابن زهير الأزدي أو شوقي بك أحمد كما ذكر الشاعر الرحَّال؛ ومن أبيات القصيدة قوله: حسب المدائح قربةً للساري ** أن المدائح بلغة الأبرار تُطوَى له أبعادُ سعي المادح *** ويصان رغمَ الوحش في الأمثار وصل الألى مدحوا جنابَ المصطفى ** أقصى مدى النقباء في المضمار مدح الحبيب بلاغة ورشاقة *** وبراعة تُغنيك عن أسمار ملح الحبيب عبادة ومهابة ** تُنجيك شرَّ مخالب الأنسار فيه الإصابة والإنابة والمنى ** يعطيك من ألطاف ربي الباري أجمل بصنعك، قد عهدتك شاعرا ق*ق تحكي بشعرك نغمةً البشَّار يا شاعرا حزت المكانة والعلا *** في أيكة الحسَّان فالأنصاري

$$
\begin{aligned}
& 1 \text { - المرجع نفسه، ص • ـ - إـ. } \\
& \text { r- المرجع نفسه، ص 0ـ } \\
& \text { r- المرجع نفسه، والصفحة نفسها. }
\end{aligned}
$$




$$
\begin{aligned}
& \text { عظَّمت سهمك في تفاصل أسُهٍٍِ *** في شركة المدَّاح باسكندار } \\
& \text { وعرضت شعرك سائغا مترنما ** تصف الرسول عزيمة الأحرار(1) }
\end{aligned}
$$

وعلى غرار وصف الأوضاع الثقافة العلمية في مصر العربية، فإن الشاعر لا يزال يُضيف إلى وصفه، كشفَ الأوضاع الاجتماعية والاقتصادية المضطربة في وطنه نيجيريا، موازناً بين المشاهدات والوقائع في البيئة المزارة وبين أوضاع بيئته الأولى التي أتى منها زائرا. وقد حضرته قصيدة في شكوى واقع الوطن النيجيري في جلسة الدعاء لبلاده العزيزة، والتي أقيمت في القاهرة. وانطلاقا من توظيفه لخبراته الثقافية ومعطياته النقدية، شرع ينقد البيئتين

$$
\text { ذكراً لفضائلِ القاهرة ومناقصِ نيجيريا كما يبدو في قوله: }
$$

$$
\begin{aligned}
& \text { حرمتْ جنة وطني قلمي ** وبقيتُ في غمومي وهمي } \\
& \text { إذ أحبُّ العود والرجع إلى ** مهبطي ومسقطي عند عمي } \\
& \text { وتُحاشيني ظروف بلدي *** من شرود أو تطاير دم } \\
& \text { أيَّ تغييب وتنفير أَرى *** في بلادي دون سبق مأتثي } \\
& \text { وغلاء عند أسواق وما *** يستقيم العيش دون دسمي } \\
& \text { ومتى أحلم أن أوصلكم *** ومتى يحلو (أيبوشي) بفمي } \\
& \text { عشتُ في مصرٍ بروحٍ أغتدي *** وأمان وسنام سلمي } \\
& \text { أشرب العذب بدون الانقطاع *** وضياء الكهرباء سَهمي } \\
& \text { ويكون العيش أكلا ناله ** أهلها رغم فشٍِّ العدم } \\
& \text { وفطوري بحليب خصب *** وغذائي رُبع ديكٍ لزم } \\
& \text { غير أن الأهل أسبوا فكرتي *** وصلهم عندي عزيز كدمي وني }
\end{aligned}
$$

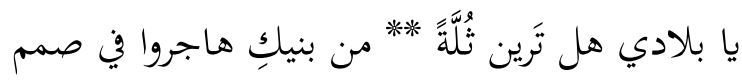

$$
\begin{aligned}
& \text { وقلوكِ إذ تعصَّتْ لهُ *** عيشة الأحرار حتى درهم } \\
& \text { فضَّلوا عيش العُبيد الآبق *** خارج الدولة رغم الوصم } \\
& \text { شغلوا أنفسهم روم الجدا ** أهملوا أعراضهم كالغنم }
\end{aligned}
$$

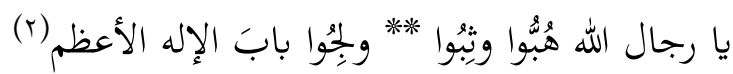


حاول الباحث قضاء أوطار المقالة بتبيين تاريخ أدب الرحلات نشأة وتطورا عند العرب وين نيجيريا، مع جعل الدراسة النموذجية لأعمال الشاعر إسحاق أيوب ببأويى الإلوري، وقد تمت الإشارة إلى مشكلة هذا البحث وأهدافه وأهميته التي من أجلها تم هذا الاختيار لتنقيب معالم الدين والثقافة والفن التي شاهدها في مصر العروبة عند انتظامه في دورة الأئمة والوعاظ العالمية، قاصدا في ضبط الحقائق مشاطرة القراء بتجاربه ومشاهدته لخلق التواصل العلمي والثقافي. ومن نتائج المقالة أن الشاعر لا تقل مقدرته الفنية ومهارته الوصفية في إيتاء الفن الرِّحَلي حقه، إذ قد وُفَّق إلى إصابة الوصف الدقيق للمظاهر الطبيعية في جغرافيتها وحيواناها، والأوضاع الثقافية في آثارها ومعطياتما، والأوضاع الاجتماعية والاقتصادية التي رآها الشاعر خلافَ ما كان يعايشها في وطنه النيجيري، فعرضها وقارن بينهما، وذكر الحلول الدسمة لصلاحية المواطنين النيجيريين إذا أرادوا مسايرة روح العصر في رقيه ونجاحه فتلتحق بلادهم بركب الأمم المتقدمة.

ويوصي الباحث أدباء العربية في نيجيريا أن يستغلُوا فرصة رحلاهم العلمية لإثراء المكتبات الأدبية العربية النيجيرية بانطباعاقم ومشاعرهم بتحاه المشاهدات والوقائع، محبّدين ما صلح من الآثار، ومحاولين تغيير ما فسد منها، كما فعل الشاعر ولو بلسانه وقلبه، فلم ييخل بإسهامه في تغيير المنكر على قدر الاستطاعة، والدعوة إلى لى وجوه الخير.

\section{References}

Al-Ḥaqīqi al-Ilory. Sulaimān Șāliḥ al-Imām. (2010). Adab al-Riḥlah 'Ind al-'Allamah alIlory. Kano, Nigeria: Maktabah Jam‘iyyah al-Abrār.

Al-Ilory, Ādam 'Abdullah. (n.d). Laqațāt min Qașā'id al-Ilory. Aghighi, Nigeria: Hai'ah alTadrīs bi Markaz al-Ta'līm al-'Arabi al-Islāmi.

Al-Murtaḍa, Muṣliḥ al-Dīn Yūsuf. (2017). Al-Ittijahāt al-Fanniyah fì Adab al-Rihlah li 'Ulamā' Bilād Yurbāa. Ilorin. Nigeria: Qism al-'Arabiyyah, Jāmi'ah Ilorin.

Al-Yasu'iy, Luis Ma'lūf. (1986). Al-Munjid fì al-Lughah wa al-A 'lām. Beirut: al-Maktabah al-Sharqiyyah.

Baba-Oye, Ishaq Ayyub. (2009). Adab al-Riḥlāt al-'Arabi. Qissah al-Riḥlah Namudhajan. Manuscript

Baba-Oye, Ishaq Ayyub. (2016). Diwān al-Qalam al-Akhdar. Ilorin, Nigeria: Maṭba'ah Kiudamilola li Khadamāt al-Kombūter wa al-Ṭibā'ah

Baba-Oye, Ishaq Ayyub. (n.d). Qașīdah Astaghil Hadha al-Majāl. Manuscript

Bodofo, Khalīl Allah Muhammad Uthman. (n.d). Dirāsah Taḥlīliyyah li Makhțūtah Fath alKhalāq fi Riḥlah Ila Mișr wa al-Hijāz wa al-'Irāq. Manuscript.

Dayf, Shauqi. (1956). Al-Riḥlāt. Cairo: Dar al-Ma‘ārif.

Ghaladanthi. Sheikhu Ahmad Sa‘īd. (1993). Harakah al-Lughah al-'Arabiyyah wa Ādābiha fì Nigeriya. Al-Riyaḍ

Ibn Manẓūr, Jamāl al-Dīn bin Makram al-Afrīqi. (1955). Lisān al-'Arab. Cairo: Dar alMa'ārif 
Al-Dād Journal

DOI: https://doi.org/10.22452/aldad.vol5no1.7

e-ISSN: 2637-1146

https://ejournal.um.edu.my/index.php/aldaad/index

Majma‘ al-Lughah al-'Arabiyyah bi al-Qāhirah. (2004). Al-Mu'jam al-Wasīt. Egypt: Maktabah al-Shurūq al-Dawliyyah.

Malete, Jāmi'ah Wilāyah Kwārā. (2014). Tarjamah al-Shā'ir fi Majmū'ah Hașād alMa'dabah. Malete, Nigeria: Mațba'ah al-Jāmi'ah. 